\title{
Activation of thiosaccharin at a polynuclear osmium cluster
}

\author{
Tamanna Pinky a, Md. Matiar Rahman a, Shishir Ghosh a,", Kazi A. Azam a, Md. Jadu Mia

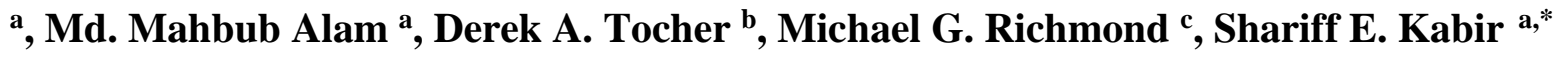 \\ ${ }^{a}$ Department of Chemistry, Jahangirnagar University, Savar, Dhaka 1342, Bangladesh \\ ${ }^{b}$ Department of Chemistry, University College London, 20 Gordon Street, London WC1H OAJ, \\ $U K$ \\ ${ }^{c}$ Department of Chemistry, University of North Texas, 1155 Union Circle, Box 305070, Denton, \\ TX 76203, USA
}

*Corresponding authors.

E-mail addresses: sghosh_006@yahoo.com (S. Ghosh); skabir_ju@yahoo.com (S.E. Kabir)

\begin{abstract}
The reaction of thiosaccharin $(\operatorname{tsacH})$ with the triosmium cluster $\left[\mathrm{Os}_{3}(\mathrm{CO})_{10}(\mathrm{NCMe})_{2}\right]$ furnishes the decacarbonyl isomers $\left[\mathrm{HOs}_{3}(\mathrm{CO})_{10}(\mu-\mathrm{S}\right.$-tsac $\left.)\right](\mathbf{1})$ and $\left[\mathrm{HOs}_{3}(\mathrm{CO})_{10}(\mu-\mathrm{N}, \mathrm{S}-1,3\right.$-tsac $\left.)\right](\mathbf{2})$ in a 3:1 ratio at room temperature. These isomers differ by the coordination mode displayed by tsac ligand. The tsac moiety functions as an edge-bridging ligand via the sulfur atom in $\mathbf{1}$ while in $\mathbf{2}$ the bridging of adjacent osmium centers is achieved through the sulfur and nitrogen groups. The ancillary hydride in both products shares the Os-Os edge that is bridged by the heterocyclic ligand. Heating 1 at $80{ }^{\circ} \mathrm{C}$ affords 2 and demonstrates that the former cluster is the product of kinetic control. The conversion of $\mathbf{1} \rightarrow \mathbf{2}$ has been investigated by DFT and the isomerization pathway elucidated. The DFT calculations confirm cluster $\mathbf{2}$ as the thermodynamically preferred isomer in this pair of products. Thermolysis of $\mathbf{2}$ in refluxing toluene affords the hexanuclear cluster $\left[\mathrm{H}_{2} \mathrm{Os}_{6}(\mathrm{CO})_{17}\left(\mu-\mathrm{C}, \mathrm{N}-1,2-\mathrm{C}_{6} \mathrm{H}_{4} \mathrm{CNSO}_{2}\right)_{2}\left(\mu_{3}-\mathrm{S}\right)\left(\mu_{4}-\mathrm{S}\right)\right]$ (3) via carbon-sulfur bond scission and subsequent capture of the extruded sulfur by the cluster core. The molecular structures for the three new clusters have been determined by single-crystal X-ray diffraction analyses.
\end{abstract}


Keywords: Polynuclear osmium clusters; Metal carbonyls; Thiosaccharin (tsacH); DFT; X-ray structures.

\section{Introduction}

Saccharin ( $\mathrm{sacH})$ and its water-soluble saccharinate salts are well-known and widely used artificial sweeteners [1]. The saccharinate anion $\left(\mathrm{sac}^{-1}\right)$, which easily forms due to the acidic nature of the heterocyclc NH moiety, exhibits versatile coordination properties and provides up to four potential donor atoms for bonding with transition metal centers based on the presence of one nitrogen and three oxygen atoms. As a consequence, the coordination chemistry of the $\mathrm{sac}^{-1}$ has been extensively studied over the years [2,3]. In comparison, scant attention has been given to thiosaccharin (tsacH) which is closely related to sacH [3-11]. The heterocyclic compound tsacH can, in principle, exist in two, principle tautomeric forms in solution (Chart 1) that parallel the wellknown lactam $\rightleftharpoons$ lactim equilibria established for dione-containing heterocycles. In the case of tsacH, the pertinent equilibrium involves the heterocyclic thione (thioamide) and the thiol (thioimine) forms of the molecule [12,13], with the thiol contributor favored computationally [14] and confirmed experimentally by NMR measurements [15].

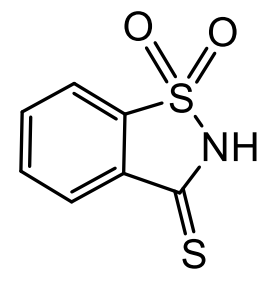

thione

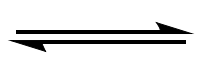

Chart 1. Major tautomers of thiosaccharin (tsacH).

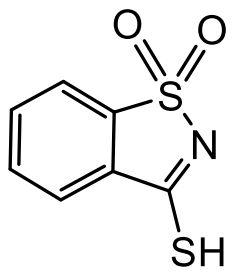

thiol

A recent theoretical study [14] has revealed some notable differences between sacH and tsacH. While the negative charge at the $\mathrm{N}$-atom of sac remains essentially unchanged upon deprotonation, it decreases significantly in tsac, but the negative charge at the mono-coordinated chalcogen atom is significantly increased in the latter than in the former. These structural and electronic differences greatly facilitate favorable interactions between the thiocarbonyl moiety (soft base) of tsac and heavy metal cations such as $\mathrm{Cd}(\mathrm{II}), \mathrm{Hg}(\mathrm{II}), \mathrm{Tl}(\mathrm{I})$ or $\mathrm{Pb}(\mathrm{II})$ (soft acids) [16,17], but 
precludes its interaction with first-row divalent transition metal cations widely prevalent in saccharin-substituted compounds [3].

While numerous studies on the reactivity of sacH with metal compounds are known, to our knowledge, only two reports appear in the literature on the reaction of saccharin with low-valent metal clusters $[18,19]$. In 2006, Buck and Maas reported the isolation of the di- and tetra-ruthenium complexes, $\left[\mathrm{Ru}_{2}(\mathrm{CO})_{6}(\mu \text {-sac })_{2}\right]$ and $\left[\mathrm{Ru}_{4}(\mathrm{CO})_{12}(\mu \text {-sac })_{4}\right]$, respectively, from the reactions of $\mathrm{Ru}_{3}(\mathrm{CO})_{12}$ with excess sacH at elevated temperatures [18]. Moreover, these authors found that both sac-containing compounds function as suitable pre-catalysts for the cyclopropanation of nucleophilic alkenes with methyl diazoacetate [18], with the $\mathrm{Ru}_{4}$ system also able to catalyze the intramolecular carbenoid $\mathrm{C}-\mathrm{H}$ insertion in 2-diazoacetoacetamides to yield $\beta$ - and/or $\gamma$-lactams [20,21]. Recently, we reported the first triosmium clusters containing an ancillary sac ligand from the reactions of $\left[\mathrm{Os}_{3}(\mathrm{CO})_{10-n}(\mathrm{NCMe})_{n}\right](\mathrm{n}=1,2)$ with sacH in refluxing benzene. Scheme 1 illustrates the reaction that gives $\left[\mathrm{HOs}_{3}(\mathrm{CO})_{10}(\mu-\mathrm{N}, \mathrm{O}-1,2-\mathrm{sac})\right]$, whose reactivity with monodentate phosphines, $\mathrm{PR}_{3}(\mathrm{R}=\mathrm{Ph}, \mathrm{Th}, \mathrm{Fu})$ was examined in our report and found to afford the corresponding mono- and bis-phosphine substituted derivatives $\left[\mathrm{HOs}_{3}(\mathrm{CO})_{9}\left(\mathrm{PR}_{3}\right)(\mu-\mathrm{N}, \mathrm{O}-1,2-\mathrm{sac})\right]$ and $\left[\mathrm{HOs}_{3}(\mathrm{CO})_{8}\left(\mathrm{PR}_{3}\right)_{2}(\mu-\mathrm{N}, \mathrm{O}-1,2-\mathrm{sac})\right]$, respectively [19]. The coordinated sac ligand maintains a $\mu-$ $\mathrm{N}, \mathrm{O}$ coordination mode in the products and is believed to play a pivotal role as a spectator ligand that helps to direct the phosphine regiochemistry associated with these substitution reactions.

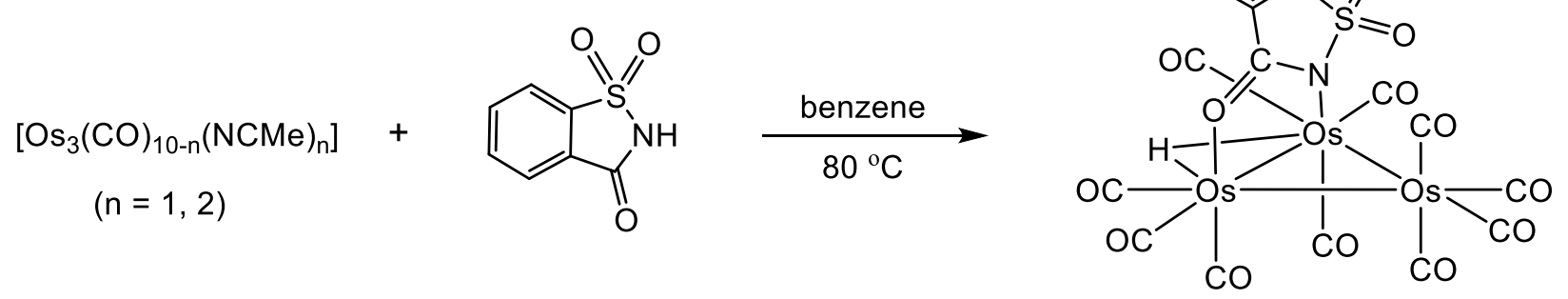

Scheme 1. Reactions of $\left[\mathrm{Os}_{3}(\mathrm{CO})_{10-\mathrm{n}}(\mathrm{NCMe})_{\mathrm{n}}\right](\mathrm{n}=1,2)$ with $\mathrm{sacH}$.

In order to compare the reactivity of sacH versus tsacH at polynuclear metal clusters, we have initiated investigations on the reaction of tsacH with low-valent metal clusters given the presence of the sulfur donor moiety in the tsacH that should furnish tsac-based products having 
novel structural architectures that utilize sulfur donation to a soft metal center(s) relative to sacH [14]. As part of this commemorative tribute to our friend and colleague, Professor Richard J. Puddephatt, we report our preliminary results on the reaction of tsacH with $\left[\mathrm{Os}_{3}(\mathrm{CO})_{10}(\mathrm{NCMe})_{2}\right]$ that affords the isomeric tsac-substituted clusters $\mathbf{1}$ and $\mathbf{2}$. The coordination mode exhibited by the tsac ligand in these new products has been established by X-ray crystallography, and the pathway for isomerization has been elucidated by DFT calculations. The thermal stability of the isolated $\left[\mathrm{HOs}_{3}(\mathrm{CO})_{10}(\mu\right.$-tsac $\left.)\right]$ clusters was also investigated.

\section{Experimental section}

\subsection{General}

All reactions were carried out under a dry nitrogen atmosphere using standard Schlenk techniques unless otherwise noted. Reagent grade solvents were dried using appropriate drying agents and distilled prior to use by standard methods. Infrared spectra were recorded on a Shimadzu FTIR Prestige 21 spectrophotometer, and the NMR spectra were recorded on a Bruker Avance III HD $(400 \mathrm{MHz})$ instrument. All chemical shifts are reported in $\delta$ units and are referenced to the residual protons of the deuterated NMR solvent $\left({ }^{1} \mathrm{H}\right)$. Elemental analyses were performed by the Microanalytical Laboratory of Wazed Miah Science Research Center at Jahangirnagar University. $\mathrm{Os}_{3}(\mathrm{CO})_{12}$ was purchased from Strem Chemical Inc. and used without further purification. Saccharin ( $\mathrm{sacH}$ ) was purchased from Acros Chemicals Inc. and used as received. The cluster $\left[\mathrm{Os}_{3}(\mathrm{CO})_{10}(\mathrm{NCMe})_{2}\right]$ [22] and thiosaccharin (tsac) [11] were prepared according to published methods. All products reported herein were separated in the air by TLC plates coated with $0.25 \mathrm{~mm}$ of silica gel ( $\mathrm{HF}_{254}$-type 60, E. Merck, Germany).

\subsection{Reaction of $\left[\mathrm{Os}_{3}(\mathrm{CO})_{10}(\mathrm{NCMe})_{2}\right]$ with thiosaccharin (tsacH)}

(a) Room temperature: To a benzene solution $(20 \mathrm{~mL})$ containing $\left[\mathrm{Os}_{3}(\mathrm{CO})_{10}(\mathrm{NCMe})_{2}\right]$ $(0.13 \mathrm{~g}, 0.14 \mathrm{mmol})$ was added tsacH $(56 \mathrm{~g}, 0.28 \mathrm{mmol})$, after which the solution was allowed to stir at room temperature for $2 \mathrm{~h}$. TLC examination of the reaction revealed the presence of two new products in a 3:1 ratio representing $\mathbf{1}$ and $\mathbf{2}$, respectively. The products were isolated by chromatography using an eluent composed of cyclohexane/ $\mathrm{CH}_{2} \mathrm{Cl}_{2}(1: 1, \mathrm{v} / \mathrm{v})$ that afforded two 
bands corresponding to $\left[\mathrm{HOs}_{3}(\mathrm{CO})_{10}(\mu-\mathrm{N}, \mathrm{S}-1,3\right.$-tsac $\left.)\right](2)(32 \mathrm{mg}, 22 \%)$ and $\left[\mathrm{HOs}_{3}(\mathrm{CO})_{10}(\mu-\mathrm{S}\right.$ tsac)] (1) (0.10 g, 68\%) in order of elution. Each product was obtained as orange crystals after recrystallization from $n$-hexane/ $\mathrm{CH}_{2} \mathrm{Cl}_{2}$ at $4{ }^{\circ} \mathrm{C}$. Data for 1: Anal.Calc. for $\mathrm{C}_{17} \mathrm{H}_{5} \mathrm{NO}_{12} \mathrm{Os}_{3} \mathrm{~S}_{2}$ : C, 19.44; H, 0.48, N, 1.33. Found: C, 19.92; H, 0.54, N, 1.36\%. IR ( $\left.v_{\mathrm{CO}}, \mathrm{CH}_{2} \mathrm{Cl}_{2}\right)$ : 2114m, 2076vs, 2066s, 2028s, 2019s, 1992 $\mathrm{m} \mathrm{cm}^{-1} .{ }^{1} \mathrm{H}$ NMR $\left(\mathrm{CDCl}_{3}\right): \delta 8.00(\mathrm{~m}, 1 \mathrm{H}), 7.90(\mathrm{~m}, 1 \mathrm{H}), 7.86(\mathrm{~m}, 2 \mathrm{H})$, -17.10 (s, 1H). Data for 2: Anal.Calc. for $\mathrm{C}_{17} \mathrm{H}_{5} \mathrm{NO}_{12} \mathrm{Os}_{3} \mathrm{~S}_{2}$ : C, 19.44; H, 0.48, N, 1.33. Found: C, 19.98; H, 0.52; N, 1.37\%. IR (veO, $\left.\mathrm{CH}_{2} \mathrm{Cl}_{2}\right): 2113 \mathrm{~m}, 2076 \mathrm{~s}, 2065 \mathrm{~s}, 2029 \mathrm{~s}, 2018 \mathrm{~s}, 1994 \mathrm{w}, 1982 \mathrm{w}$ $\mathrm{cm}^{-1} .{ }^{1} \mathrm{H} \mathrm{NMR}\left(\mathrm{CDCl}_{3}\right): \delta 7.94(\mathrm{~d}, \mathrm{~J} 7.2 \mathrm{~Hz}, 1 \mathrm{H}), 7.84(\mathrm{~d}, \mathrm{~J} 7.2 \mathrm{~Hz}, 1 \mathrm{H}), 7.72(\mathrm{~m}, 2 \mathrm{H}),-13.96(\mathrm{~s}$, $1 \mathrm{H})$.

(b) Refluxing benzene: The same reaction was conducted at elevated temperature in refluxing benzene. To $20 \mathrm{~mL}$ of benzene containing tsacH $(20 \mathrm{~mL})$ at reflux was added in one portion $\left[\mathrm{Os}_{3}(\mathrm{CO})_{10}(\mathrm{NCMe})_{2}\right](0.13 \mathrm{~g}, 0.14 \mathrm{mmol})$. The solution was stirred for $2 \mathrm{~h}$ and the solution

allowed to cool to room temperature, at which time TLC analysis revealed the presence of clusters 1 and 2 where the latter represented the major product. The presence of some decomposition material was noted based on material that remained at the origin of the TLC plate. The solvent was removed under vacuum and the residue purified as described above to give clusters $\mathbf{1}(8 \%)$ and 2 $(52 \%)$ after crystallization from $n$-hexane $/ \mathrm{CH}_{2} \mathrm{Cl}_{2}$ at $4{ }^{\circ} \mathrm{C}$.

\subsection{Conversion of 1 to 2}

A benzene solution $(15 \mathrm{~mL})$ of $1(15 \mathrm{mg}, 0.014 \mathrm{mmol})$ was heated to reflux for $3 \mathrm{~h}$. The orange color of the solution turned to yellow over time. A similar work-up and chromatographic separation, as described above, afforded $\left[\mathrm{HOs}_{3}(\mathrm{CO})_{10}(\mu-\mathrm{N}, \mathrm{S}-1,3-\right.$ tsac $\left.)\right](2)(12 \mathrm{mg}, 80 \%)$.

\subsection{Thermolysis of 2}

A toluene solution $(20 \mathrm{~mL})$ of $2(50 \mathrm{mg}, 0.048 \mathrm{mmol})$ was heated to reflux for $4 \mathrm{~h}$. The solvent was removed under reduced pressure and the residue chromatographed by TLC on silica gel. Elution with $n$-hexane/ $\mathrm{CH}_{2} \mathrm{Cl}_{2}\left(2: 3\right.$, v/v) afforded $\left[\mathrm{H}_{2} \mathrm{Os}_{6}(\mathrm{CO})_{17}\left(\mu-\mathrm{C}, \mathrm{N}-1,2-\mathrm{C}_{6} \mathrm{H}_{4} \mathrm{CNSO}_{2}\right)_{2}\left(\mu_{3}-\right.\right.$ $\left.\mathrm{S})\left(\mu_{4}-\mathrm{S}\right)\right](3)(18 \mathrm{mg}, 38 \%)$ as orange crystals after recrystallization from $n$-hexane $/ \mathrm{CH}_{2} \mathrm{Cl}_{2}$ at $4{ }^{\circ} \mathrm{C}$. Data for 3: Anal.Calc. for $\mathrm{C}_{31} \mathrm{H}_{10} \mathrm{~N}_{2} \mathrm{O}_{21} \mathrm{Os}_{6} \mathrm{~S}_{4} \cdot 2 \mathrm{CH}_{2} \mathrm{Cl}_{2}$ : C, 18.13; H, 0.65; N, 1.28. Found: C, 18.44; $\mathrm{H}, 0.69 ; \mathrm{N}, 1.31 \%$. IR ( $\left.v_{\mathrm{CO}}, \mathrm{CH}_{2} \mathrm{Cl}_{2}\right): 2122 \mathrm{~s}, 2102 \mathrm{~s}, 2073 \mathrm{vs}, 2047 \mathrm{~s}, 2035 \mathrm{~m}, 2016 \mathrm{~s}, 1993 \mathrm{~m}, 1979 \mathrm{~m}$ 
$\mathrm{cm}^{-1} .{ }^{1} \mathrm{H} \mathrm{NMR}\left(\mathrm{CDCl}_{3}\right)$ : both isomers: $\delta 8.12(\mathrm{~m}, 1 \mathrm{H}), 8.06(\mathrm{~m}, 1 \mathrm{H}), 8.01(\mathrm{~m}, 1 \mathrm{H}), 7.95-7.82(\mathrm{~m}$, 5H); hydride region: major isomer: $-14.29(\mathrm{~d}, \mathrm{~J} 2.0 \mathrm{~Hz}, 1 \mathrm{H}),-17.74(\mathrm{~d}, \mathrm{~J} 2.0 \mathrm{~Hz}, 1 \mathrm{H})$; minor isomer: -14.37 (d, J 2.4 Hz, 1H), -18.09 (d, J $2.4 \mathrm{~Hz}, 1 \mathrm{H})$. Major : minor ca. 5:1.

\subsection{Crystal structure determinations}

Single crystals of 1-3 suitable for X-ray diffraction analysis were grown by slow diffusion of hexane into a $\mathrm{CH}_{2} \mathrm{Cl}_{2}$ solution containing each product. Suitable crystals were mounted on an Agilent Super Nova dual diffractometer (Agilent Technologies Inc., Santa Clara, CA) using a Nylon loop and Paratone oil and the diffraction data were collected at 150(1) K using Mo-Ka radiation $(\lambda=0.71073)$. Unit cell determination, data reduction, and absorption corrections were carried out using CrysAlisPro [23]. The structures were solved with the ShelXS [24] structure solution program by direct methods (for 2 and 3) or with the Superflip [25] structure solution program using Charge Flipping (for 1) and refined by full-matrix least-squares on the basis of $F^{2}$ using ShelXL [24,26] within the OLEX2 [27] graphical user interface. All non-hydrogen atoms were anisotropically refined while the hydrogen atoms (except those directly bonded to metals) were included using a riding model. The bridging hydride that spans the Os(1)-Os(2) vector in cluster 2 and the two hydrides in 3 at the Os(1)-Os(3) and Os(2)-Os(3) bonds could not be located during data refinement. In these two cases, the location of each hydride was established by electronic structure calculations. Pertinent crystallographic parameters are given in Table 1.

\subsection{Computational methodology}

All calculations were performed with the hybrid DFT functional B3LYP, as implemented by the Gaussian 09 program package [28]. This functional utilizes the Becke three-parameter exchange functional (B3) [29], combined with the correlation functional of Lee, Yang and Parr (LYP) [30]. The osmium atoms were described by Stuttgart-Dresden effective core potentials (ecp) and an SDD basis set, while the 6-31G(d') basis set was employed for the remaining atoms. The reported geometries were fully optimized without restrictions, and the analytical second derivatives were evaluated and found to possess only positive eigenvalues for ground-state minima and one negative eigenvalue for transition-state structures. The geometry-optimized structures have been drawn with the JIMP2 molecular visualization and manipulation program [31]. 


\section{Results and discussion}

\subsection{Reaction of $\left[\mathrm{Os}_{3}(\mathrm{CO})_{10}(\mathrm{NCMe})_{2}\right]$ with thiosaccharin (tsacH)}

Treatment of $\left[\mathrm{Os}_{3}(\mathrm{CO})_{10}(\mathrm{NCMe})_{2}\right]$ and tsacH at room temperature in benzene furnishes a binary mixture of products that were subsequently identified as $\left[\mathrm{HOs}_{3}(\mathrm{CO})_{10}(\mu-\mathrm{S}\right.$-tsac) $](\mathbf{1})$ and $\left[\mathrm{HOs}_{3}(\mathrm{CO})_{10}(\mu-\mathrm{N}, \mathrm{S}-1,3-\mathrm{tsac})\right](2)$. The yields for these products are $68 \%$ and $22 \%$, respectively. Scheme 2 shows the products from this reaction. In the case of $\mathbf{1}$, the tsac ligand bridges an osmiumosmium edge via the sulfur and supports a pathway that involves the oxidative addition of the S$\mathrm{H}$ bond in the thiol tautomer of tsacH depicted in Chart 1. Cluster 2, which derives from the formal oxidative addition of the $\mathrm{N}-\mathrm{H}$ bond in the thione tautomer, is an isomer of $\mathbf{1}$ where the tsac ligand bridges adjacent osmium centers through the nitrogen and sulfur atoms of the heterocyclic moiety.
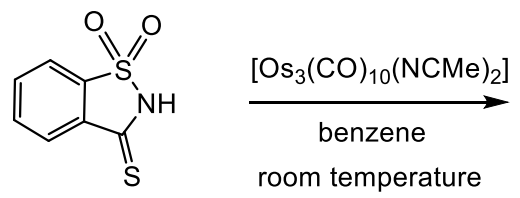

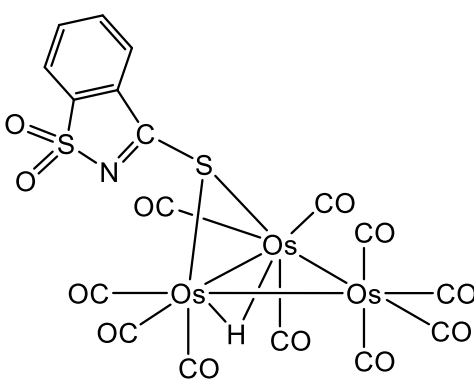

1

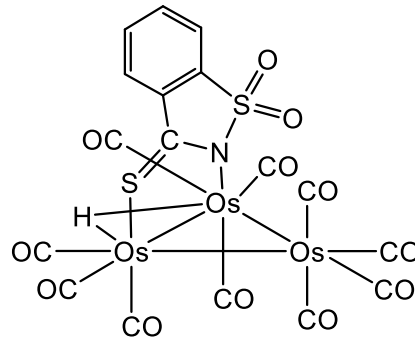

2

Scheme 2. Reaction of $\left[\mathrm{Os}_{3}(\mathrm{CO})_{10}(\mathrm{NCMe})_{2}\right]$ with tsacH.

The effect of temperature on the nature of the products and their composition was next examined. Heating an equimolar mixture of tsacH and $\left[\mathrm{Os}_{3}(\mathrm{CO})_{10}(\mathrm{NCMe})_{2}\right]$ in refluxing benzene gave clusters 1 and 2 with a reversal in their ratio that favored cluster 2 (52\%) relative to 1 (8\%). Subsequent control experiments confirmed that $\mathbf{1}$ isomerizes to $\mathbf{2}$ in refluxing benzene; these results strongly support $\mathbf{1}$ as the kinetic substitution product with $\mathbf{2}$ formed as the thermodynamically favored isomer, a premise verified by electronic structure calculations (vide infra). Both new products have been fully characterized by elemental analyses, IR and ${ }^{1} \mathrm{H}$ NMR spectroscopies, and their solid-state structures established by X-ray crystallography. 
Two crystallographically independent molecules were found in the asymmetric unit of $\mathbf{1}$. Since no significant differences exist between these molecules, we will restrict our discussion to the structure that is shown in Fig. 1, whose caption contains selected bond lengths and angles. The molecule contains 48e, assuming the bridging sulfur moiety serves as a three-electron donor, and metallic core displays an isosceles triangle of osmium atoms [Os(1)-Os(2) 2.8451(5), Os(1)-Os(3) 2.8460(6) and Os(2)-Os(3) 2.8524(5) Å] ligated by ten carbonyls, along with edge-bridging tsac and hydride ligands that share a common Os-Os edge. The tsac ligand symmetrically bridges the Os(1)-Os(2) vector through the S(1) center and exhibits a mean Os-S distance of $2.423 \AA$ that falls within the range reported for related clusters [32-37]. The hydride ligand, which was located from a difference map, spans the Os(1)-Os(2) edge and lies on the opposite face of the metal triangle relative the bridging $\mathrm{S}(1)$ moiety. Three carbonyls are distributed similarly at the Os(1) and Os(2) centers with the remaining four carbonyls bound to the remote Os(3) center. The carbon-sulfur bond distance in 1 [C(21)-S(1) 1.781(9) $\AA$ ] is ca. $0.1 \AA$ longer than that observed in 2 [1.672(13) $\AA$ ] , while the carbon-nitrogen bond distance of 1.261(11) $\AA$ is shorter than that distance found in 2 [1.321(17) $\mathrm{A}]$ (vide infra) indicating that that the tsac ligand more closely resembles the thiol form in 1 (Chart 1). We also examined the bonding in 1 by DFT, and the B3LYP-optimized structure of A is shown alongside the experimentally determined solid-state structure (Fig. 1). The computed structure of A closely parallels that of the crystallographic structure.

\section{Place Figure 1 Here}

The solution spectroscopic data of 1 reveal that the solid-state structure persists in solution. The IR spectrum exhibits six absorptions within the range $2114-1992 \mathrm{~cm}^{-1}$ for the ten terminal carbonyls present in the molecule, while the ${ }^{1} \mathrm{H}$ NMR spectrum displays an upfield singlet $\delta-17.10$ for the bridging hydride together with three multiplets centered at $\delta 8.00,7.90$ and 7.86 in 1:1:2 intensity ratio due to the tsac protons.

The asymmetric unit of $\mathbf{2}$ also contains two independent molecules that do not show any significant structural differences, allowing us to limit our discussion to the structure that is depicted in Fig. 2. Selected bond distances and angles for $\mathbf{2}$ are listed in the figure caption. The cluster core contains an osmium triangle with Os-Os distances that range from 2.8776(6) to 2.9301(6) $\AA$ [Os(1)-Os(2) 2.9301(6); Os(1)-Os(3) 2.9052(7); Os(2)-Os(3) 2.8776(6) А]. The tsac donor functions as a bridging ligand and it spans the Os(1)-Os(2) bond, the longest osmium-osmium edge, lying almost perpendicular to the metallic plane. The nitrogen of the tsac ligand is coordinated to the Os(2) center while the $S(1)$ thiocarbonyl moiety is bound at the Os(1) center. 2 may be 
viewed as an electron-precise cluster that possesses 48 valence electrons with the heterocyclic ligand contributing $3 \mathrm{e}$ to the total electron count. While the hydride ligand was not located during data refinement, it may be confidently assigned to a locus at the Os(1)-Os(2) vector based on the angular arrangement displayed by the $\mathrm{C}(1) \mathrm{O}(1)$ and $\mathrm{C}(4) \mathrm{O}(4)$ groups that reside in the plane of the three osmium atoms. Here the widening of the OC-Os-Os angles [C(1)-Os(1)-Os(2) 119.6(4) and $\mathrm{C}(4)-\mathrm{Os}(2)-\mathrm{Os}(1) 117.7(4)^{\circ}$ ] provide space for the hydride to bridge the Os(1)-Os(2) edge in a manner similar to the hydride ligand in the corresponding saccharinate analog $\left[\mathrm{HOs}_{3}(\mathrm{CO})_{10}(\mu-\mathrm{N}, \mathrm{O}-\right.$ 1,2-sac)] [19]. The location of the hydride at the heterocyclic bridged Os-Os bond receives additional support from the comprehensive report recently published by us where the energies of hydride isomers at related heterocyclic-bridged triosmium clusters were examined by DFT [38]. Of the numerous hydride isomers computationally analyzed in the latter study, the thermodynamic locus for hydride was found to coincide with the Os-Os bond that was also bridged by the ancillary heterocycle [38]. The DFT-optimized structure of $\mathbf{E}$ is displayed alongside the solid-state structure of $\mathbf{2}$ in Fig. 1. The computed structure of $\mathbf{E}$ shows excellent agreement with the crystallographic structure.

\section{Place Figure 2 Here}

The solution spectroscopic data of $\mathbf{2}$ are consistent with the solid-state structure. The IR spectrum shows several absorptions between 2113-1982 $\mathrm{cm}^{-1}$ that confirms the presence of terminally bound carbonyl groups in 2 . The ${ }^{1} \mathrm{H}$ NMR spectrum displays an upfield singlet at $\delta-$ 13.96 attributed to the bridging hydride in addition to resonances in the aromatic region for the tsac protons.

\subsection{DFT modeling of the isomerization of $\mathbf{1} \rightarrow \mathbf{2}$}

DFT calculations on the isomerization of $\mathbf{1}$ to $\mathbf{2}$ were conducted in order to provide further insight into the actual steps involved in this process. Figs. 3 and 4 show the DFT-optimized structures and potential energy surface (PES), respectively, for this reaction that consists of four distinct steps. The first step in the process involves the attack of the pendant tsac nitrogen on one of the edge-bridged osmium atoms in A to give the 50e cluster $\mathbf{B}$. The reaction proceeds via TSAB and this transition state is the rate-limiting step on the PES, lying $30.0 \mathrm{kcal} / \mathrm{mol}$ above A. The formation of the Os- $\mathrm{N}$ bond in $\mathbf{B}$ promotes the cleavage of the hydride-bridged Os-Os bond, which in turn gives a terminal hydride at the other osmium center in the edge-bridged bond not subject to 
nitrogen attack. Both the coordinated nitrogen and the terminal hydride ligands in $\mathbf{B}$ occupy axial sites in the expanded cluster polyhedron. The expansion of the Os 3 core computed in $\mathbf{B}$ is understood within the tenets of Polyhedral Skeletal Electron Pair (PSEP) Theory, which supports this formal arachno $\rightarrow$ hypho transformation [39]. $\mathbf{B}$ evolves to $\mathbf{C}$ as the Os-S bond in the fourmembered heterocyclic ring breaks and migrates to the adjacent osmium center that contains the terminal hydride ligand through TSBC. The sulfur undergoes a major change in its coordination mode in $\mathbf{B} \rightarrow \mathbf{C}$ that aids the reformation of the Os-Os bond as the donor count of the sulfur is reduced from $3 \mathrm{e}$ to $1 \mathrm{e}$. $\mathbf{C}$ is electron precise with $48 \mathrm{e}$ and is $3.2 \mathrm{kcal} / \mathrm{mol}$ more stable than $\mathbf{A}$. Hydride migration from the non-ligand bridged Os-Os edge in $\mathbf{C}$ to the thermodynamically favored tsac-bridged Os-Os bond in $\mathbf{E}$ occurs via species $\mathbf{D}$ that contains an interstitial $\mu_{3}-\mathrm{H}$ ligand which lies $9.5 \mathrm{kcal} / \mathrm{mol}$ and 11.5 . kcal/mol above the hydride-bridged species $\mathbf{C}$ and $\mathbf{E}$, respectively. Similar hydride mobility about related $\mathrm{Ru}_{3}$ and $\mathrm{Os}_{3}$ cluster frameworks has been the subject of earlier reports from our group [40]. Finally, the isomerization reaction is exergonic and liberates $5.2 \mathrm{kcal} / \mathrm{mol}$.

\section{Place Figures 3 and 4 Here}

\subsection{Thermolysis of $\left[\mathrm{HOs}_{3}(\mathrm{CO})_{10}(\mu-N, S-1,3-t s a c)\right]$ (2)}

The stability of $\mathbf{2}$ was also investigated at elevated temperature in refluxing toluene to probe the feasibility of generating a face-capping tsac ligand since the ancillary heterocycle can, in principle, serve as a 5e donor and cap one of the two triangular faces via the $\mu_{3}-\mathrm{N}, \mathrm{S}-1,3$-tsac moiety upon CO loss in $\mathbf{2}$. Thermolysis of $\mathbf{2}$ in toluene did not provide evidence for the expected tsaccapped cluster $\left[\mathrm{HOs}_{3}(\mathrm{CO})_{9}\left(\mu_{3}-\mathrm{N}, \mathrm{S}-1,3-\mathrm{tsac}\right)\right]$ but instead furnished the hexametallic cluster $\left[\mathrm{H}_{2} \mathrm{Os}_{6}(\mathrm{CO})_{17}\left(\mu-\mathrm{C}, \mathrm{N}-1,2-\mathrm{C}_{6} \mathrm{H}_{4} \mathrm{CNSO}_{2}\right)_{2}\left(\mu_{3}-\mathrm{S}\right)\left(\mu_{4}-\mathrm{S}\right)\right](3)$ in $38 \%$ yield (Scheme 3$)$, after the usual chromatographic separation and work up. The transformation of $\mathbf{2} \rightarrow \mathbf{3}$ is complicated and requires a carbon-sulfur bond scission of the thiocarbonyl moiety in $\mathbf{2}$, followed by cluster dimerization. The formation of two new bridging sulfide moieties accompanies the process. 


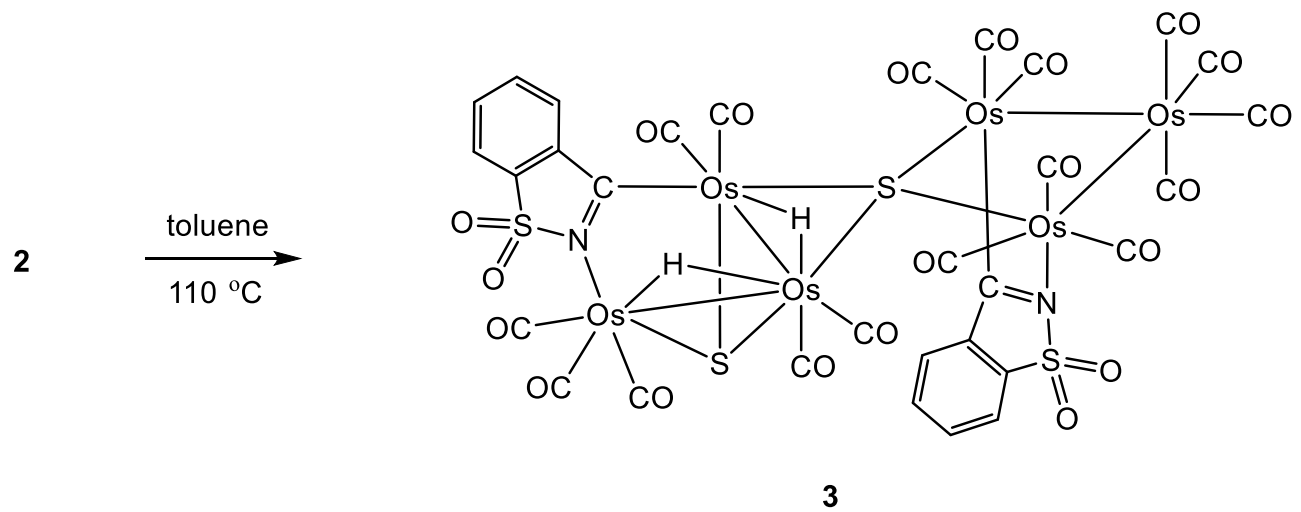

Scheme 3. Thermolysis product obtained from of $\mathbf{2}$ in refluxing toluene.

The solid-state structure of $\mathbf{3}$ was unequivocally determined by single-crystal X-ray diffraction analysis with the ORTEP diagram of the molecular structure depicted in Fig. 5. Cluster 3 co-crystallizes with two molecules of $\mathrm{CH}_{2} \mathrm{Cl}_{2}$. The molecule consists of two Os 3 units that are linked by a single $\mu_{4}-\mathrm{S}(2)$ ligand while the lone $\mu_{3}-\mathrm{S}(1)$ moiety caps one of the Os 3 units. Each trimetallic unit in $\mathbf{3}$ exhibits an opened triangular frame of osmium atoms that contains two formal Os-Os bonds. The expanded polyhedron in each $\mathrm{Os}_{3}$ unit is traced to its 50e count, which in turn, leads to a total electron count of 100 -valence electrons for $\mathbf{3}$, assuming the $\mu_{4}-\mathrm{S}(2)$ and $\mu_{3}-\mathrm{S}(1)$ ligands function as 6e and 4e donor ligands, respectively. While the two Os-Os bond lengths in one Os3 unit are almost identical [Os(5)-Os(6) 2.8933(3) and Os(4)-Os(6) 2.8962(3) ^], the related bond distances in the other Os3 unit differ significantly [Os(1)-Os(3) 2.9184(3) and Os(2)-Os(3) 2.8031(3) $\AA$ ]. The opened edge in each $\mathrm{Os}_{3}$ unit is bridged by a single $\mathrm{C}_{6} \mathrm{H}_{4} \mathrm{CNSO}_{2}$ ligand through the carbon and nitrogen atoms in the five-membered ring of the heterocyclic auxiliary. The Os-N and Os- $\mathrm{C}$ bond distances involving the heterocyclic ligand range from 2.135(5) $\AA$ [Os(1)-N(1)] to 2.017(6) $\AA$ [Os(2)-C(18)]. The mean Os-S(1) bond distance of 2.4086(15) $\AA$ for the triply bridged ligand is slightly shorter than the average Os-S(2) bond distance of 2.4518(15) $\AA$ involving the $\mu_{4^{-}}$ $\mathrm{S}$ ligand; both sets of Os-S distances are within the range reported in literature for related clusters [32-37].

\section{Place Figure 5 Here}

The ${ }^{1} \mathrm{H}$ NMR spectrum of $\mathbf{3}$ displays a pair of diastereomers based on high-field hydrides at $\delta-14.29$ and $-17.74\left({ }^{2} \mathrm{~J}_{\mathrm{H}-\mathrm{H}} 2.0 \mathrm{~Hz}\right.$; major $)$, and $\delta-14.37$ and $-18.09\left({ }^{2} \mathrm{~J}_{\mathrm{H}-\mathrm{H}} 2.4 \mathrm{~Hz}\right.$; minor $)$ in a 5:1 ratio. No equilibration between the two isomers has been observed at room temperature for a 
sample checked by EXSY ${ }^{1} \mathrm{H}$ NMR spectroscopy, and this result is mirrored by VT ${ }^{1} \mathrm{H}$ NMR examination at temperatures below $0{ }^{\circ} \mathrm{C}$. The vicinal coupling exhibited by the hydrides suggests that they share adjacent edges in $\mathbf{3}$, and we propose the Os(1)-Os(3) and Os(2)-Os(3) vectors serve as the preferred sites for the crystallographically unobserved hydrides. Both hydrides may be accommodated on the metallic face opposite the capping $\mu_{3}-\mathrm{S}(1)$ ligand where the expanded OsOs- $\mathrm{CO}$ bond angles involving the $\mathrm{C}(2) \mathrm{O}(2), \mathrm{C}(4) \mathrm{O}(4)$, and $\mathrm{C}(6) \mathrm{O}(6)$ ligands facilitate their location [41]. Here the bond angles for the pertinent linkages are C(2)-Os(1)-Os(3) 116.0(2), C(6)Os(3)-Os(1) 119.12(18), C(6)-Os(3)-Os(2) 119.61(19) and C(4)-Os(2)-Os(3) 118.61(19) . The DFT-structure of F1 is shown in Fig. 5 alongside the experimental structure with good correlation between the two noted.

Before the identity of the second diastereomer is addressed, the probable location of the hydrides needs to be established. We propose that the hydrides in all potential diastereomers maintain their location about the $\mathrm{Os}(1)-\mathrm{Os}(3)$ and $\mathrm{Os}(2)-\mathrm{Os}(3)$ vectors in the face-capped portion of $\mathbf{3}$, and that the stereoisomerism exhibited by $\mathbf{3}$ in solution is best accounted by different orientations of the $\mathrm{Os}_{3}(\mathrm{CO})_{10}\left(\mu-\mathrm{C}, \mathrm{N}-1,2-\mathrm{C}_{6} \mathrm{H}_{4} \mathrm{CNSO}_{2}\right)$ and $\mathrm{H}_{2} \mathrm{Os}_{3}(\mathrm{CO})_{7}(\mu-\mathrm{C}, \mathrm{N}-1,2-$ $\left.\mathrm{C}_{6} \mathrm{H}_{4} \mathrm{CNSO}_{2}\right)\left(\mu_{3}-\mathrm{S}\right)$ units relative to the ligating $\mu_{4}-\mathrm{S}$ ligand. Fig. 6 shows the energy ordering for the four possible stereoisomers based on cluster 3 . The additional structures represented by F2-F4 are all are consistent with the second stereoisomer observed in solution by ${ }^{1} \mathrm{H}$ NMR spectroscopy. The major difference between the four computed diastereomers concerns the rotation of the $\mathrm{Os}_{3}(\mathrm{CO})_{10}\left(\mu-\mathrm{C}, \mathrm{N}-1,2-\mathrm{C}_{6} \mathrm{H}_{4} \mathrm{CNSO}_{2}\right)$ unit relative to the $\mathrm{H}_{2} \mathrm{Os}_{3}(\mathrm{CO})_{7}\left(\mu-\mathrm{C}, \mathrm{N}-1,2-\mathrm{C}_{6} \mathrm{H}_{4} \mathrm{CNSO}_{2}\right)\left(\mu_{3}-\right.$ $S)\left(\mu_{4}-S\right)$ anchor. The structure computed for $\mathbf{F} 1$ is the most stable and corresponds to the solidstate, and we suggest that $\mathbf{F 2}$ serves as the second species present in solution given its greater stability relative to $\mathbf{F 3}$ and $\mathbf{F 4}$. The energy difference $(\Delta \mathrm{G})$ between $\mathbf{F 1}$ and $\mathbf{F 2}$ is small and favors F1 by $2.6 \mathrm{kcal} / \mathrm{mol}$.

\section{Place Figure 6 Here}

The gross structural features and solution dynamics of $\mathbf{3}$ are similar to those of $\left[\mathrm{H}_{2} \mathrm{Oss}_{6}(\mathrm{CO})_{17}(\mu-\mathrm{HC}=\mathrm{NR})_{2}\left(\mu_{3}-\mathrm{S}\right)\left(\mu_{4}-\mathrm{S}\right)\right]\left(\mathrm{R}=\mathrm{C}_{6} \mathrm{H}_{5} ; \mathrm{C}_{6} \mathrm{H}_{4}-p-\mathrm{F}\right)$ which were obtained along with other products from the thermolysis of $\left[\mathrm{HOs}_{3}(\mathrm{CO})_{9}(\mu-\mathrm{HC}=\mathrm{NR})\left(\mu_{3}-\mathrm{S}\right)\right]$ in boiling octane [33]. So, it is not unreasonable to suggest a similar sulfido-capped intermediate $\left[\mathrm{HOs}_{3}(\mathrm{CO})_{9}(\mu-\mathrm{N}, \mathrm{C}-1,2-\right.$ $\left.\left.\mathrm{C}_{6} \mathrm{H}_{4} \mathrm{CNSO}_{2}\right)\left(\mu_{3}-\mathrm{S}\right)\right]$ for the formation of $\mathbf{3}$ from $\mathbf{2}$ that can be formed via an initial decarbonylation in 2 , followed by the activation of the thiocarbonylic sulfur group to promote the transfer of 
exocyclic sulfur moiety to the interior of the cluster core. The proposed intermediate was examined by DFT and the optimized structure of the putative species is shown in Fig. 7. The scission of one of the Os-Os bonds in this intermediate is consistent with its 50e count and PSEP Theory. Aggregation of this intermediate, coupled with the requisite ligand redistribution observed for the abovementioned reactions [33], could certainly furnish $\mathbf{3}$ as shown in Scheme 4.

\section{Place Figure 7 Here}

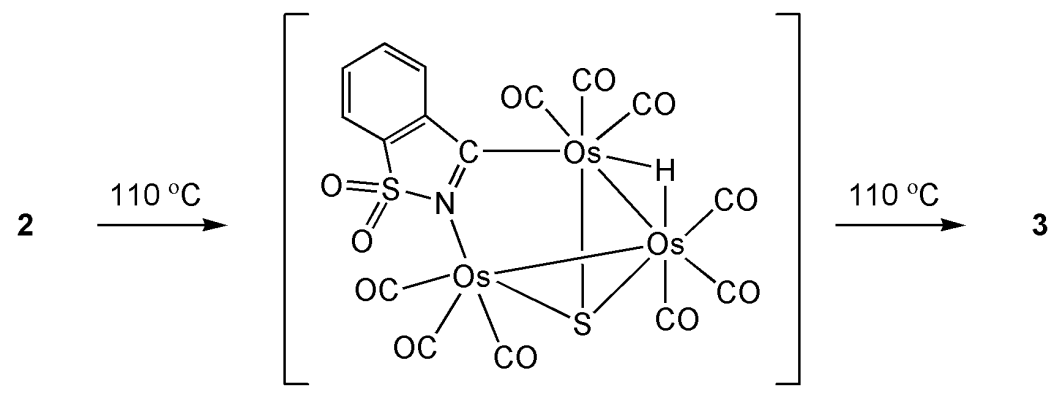

Scheme 4. Formation of $\mathbf{3}$ via the 2 -derived intermediate $\left[\mathrm{HOs}_{3}(\mathrm{CO})_{9}(\mu-\mathrm{C}, \mathrm{N}-1,2-\right.$ $\left.\left.\mathrm{C}_{6} \mathrm{H}_{4} \mathrm{CNSO}_{2}\right)\left(\mu_{3}-\mathrm{S}\right)\right]$.

\section{Conclusions}

We have presented data on the first reported reaction of tsacH with a low-valent triosmium cluster. The reaction between the labile cluster $\left[\mathrm{Os}_{3}(\mathrm{CO})_{10}(\mathrm{NCMe})_{2}\right]$ and tsacH at room temperature furnishes the isomeric triosmium clusters $\left[\mathrm{HOs}_{3}(\mathrm{CO})_{10}(\mu-\mathrm{S}\right.$-tsac)] (1) and $\left[\mathrm{HOs}_{3}(\mathrm{CO})_{10}(\mu-\mathrm{N}, \mathrm{S}-1,3-\mathrm{tsac})\right]$ (2) containing an ancillary tsac ligand. Cluster 1 represents the product of kinetic control and transforms into 2 at elevated temperature. Thermolysis of 2 at 110 ${ }^{\circ} \mathrm{C}$ afforded the hexanuclear cluster $\left[\mathrm{H}_{2} \mathrm{Os}_{6}(\mathrm{CO})_{17}\left(\mu-\mathrm{C}, \mathrm{N}-1,2-\mathrm{C}_{6} \mathrm{H}_{4} \mathrm{CNSO}_{2}\right)_{2}\left(\mu_{3}-\mathrm{S}\right)\left(\mu_{4}-\mathrm{S}\right)\right](3)$. We have suggested that formation of $\mathbf{3}$ proceed via the intermediate $\left[\mathrm{HOs}_{3}(\mathrm{CO})_{9}(\mu-\mathrm{C}, \mathrm{N}-\right.$ $\left.\left.\mathrm{C}_{6} \mathrm{H}_{4} \mathrm{CNSO}_{2}\right)_{2}\left(\mu_{3}-\mathrm{S}\right)\right]$ which is formed by extrusion of the thiocarbonylic sulfur by the cluster core.

\section{Acknowledgments}


Financial support from the Ministry of Education, the Government of the People's Republic of Bangladesh (SG) and the Robert A. Welch Foundation (Grant B-1093-MGR) is acknowledged. The DFT calculations were performed at UNT through CASCaM, which is an NSF-supported facility (CHE-1531468).

\section{Appendix A. Supplementary material}

CCDC 1870291 (for 1), 1870290 (for 2), and 1870293 (for 3) contain the supplementary crystallographic data for this paper. These data can be obtained free of charge from The Cambridge Crystallographic Data Centre via www.ccdc.cam.ac.uk/data_request/cif. Atomic coordinates and energies for all DFT-optimized structures are available upon request (MGR). 


\section{References}

[1] L.O. Nabors, C.G. Robert, Alternative Sweeteners, 2nd ed., Marcel Dekker, New York, 1991.

[2] E.J. Baran, Quím. Nova 28 (2005) 326.

[3] E.J. Baran, V.T. Yilmaz, Coord. Chem. Rev. 250 (2006) 1980.

[4] M.K. Corpinot, R.Guo, D.A. Tocher, A.B.M. Buanz, S. Gaisford, S.L. Price, D.-K. Bučar, Cryst. Growth Des. 17 (2017) 827.

[5] P.C. Andrews, R.L. Ferrero, C.M. Forsyth, P.C. Junk, J.G. Maclellan, R.M Peiris, Organometallics 30 (2011) 6283.

[6] (a) R.A. Burrow, G.Z. Belmonte, V. Dorn, M. Dennehy, Inorg. Chim. Acta 450 (2016) 39; (b) M. Dennehy, G.P. Tellería, S.H. Tarulli, O.V. Quinzani, S.D. Mandolesi, J.A. Guida, G.A.

Echeverría, O.E. Piro, E.E. Castellano, Inorg. Chim. Acta 360 (2007) 3169; (c) M. Dennehy, G.P. Tellería, O.V. Quinzani, G.A. Echeverría, O.E. Piro, E.E. Castellano, Inorg. Chim. Acta 362 (2009) 2900; (d) M. Dennehy, R.M. Ferullo, O.V. Quinzani, S.D. Mandolesi, N. Castellani, M. Jennings, Polyhedron 27 (2008) 2243; (e) F. Delgado, E. Freire, R. Baggio, V.G. Padro, V. Dorn, M. Dennehy, Inorg. Chim. Acta 479 (2018) 266.

[7] (a) M. Dennehy, S.D. Mandolesi, O.V. Quinzani, M. Jennings, Z. Anorg. Allg. Chem. 633 (2007) 2746; (b) M. Dennehy, O.V. Quinzani, R. Faccio, E. Freire, Á.W. Mombrú, Acta Cryst. C68 (2012) m12; (c) M. Dennehy, O.V. Quinzani, A. Granados, R.A. Burrow, Polyhedron 29 (2010) 1344; (d) M. Dennehy, O.V. Quinzani, R.M. Ferullo, A. Granados, R.A. Burrow, Inorg. Chim. Acta 377 (2011) 77.

[8] (a) D.R. Pérez, S.H. Tarulli, O.V. Quinzania, J. Dristas, R. Faccio, L. Suescun, A.W. Mombrú, Z. Anorg. Allg. Chem. 633 (2007) 1066; (b) S.H. Tarulli, O.V. Quinzani, O.E. Piro, E.E. Castellano, E.J. Baran, Z. Anorg. Allg. Chem. 629 (2003) 1975; (c) S.H. Tarulli, O.V. Quinzani, S.D. Mandolesi, J.A. Guida, G.A. Echeverría, O.E. Piro, E.E. Castellano, Z. Anorg. Allg. Chem. 635 (2009) 1604; (d) S.H. Tarulli, O.V. Quinzani, E.J. Baran, O.E. Piro, E.E. Castellano, J. Mol. Struct. 656 (2003) 161.

[9] (a) S.A. Al-Jibori, M.H.S. Al-Jibori, G. Hogarth, Inorg. Chim. Acta 398 (2013) 117; (b) S.A. Al-Jibori, Q.K.A. Al-Jibori, H. Schmidt, K. Merzweiler, C. Wagner, G. Hogarth, Inorg. Chim. Acta 402 (2013) 69; (c) S.A. Al-Jibori, A.T. Habeeb, G.H.H. Al-Jibori, N.A. Dayaaf, K. Merzweiler, C. Wagner, H. Schmidt, G. Hogarth, Polyhedron 67 (2014) 338; (d) S.A. Al-Jibori, 
W.J. Hameed, A.S. Al-Jibori, S. Basak-Modi, C. Wagner, G. Hogarth, Inorg. Chim. Acta 479 (2018) 197.

[10] S.A. Al-Jibori, G.H. Al-Jibori, L.J. Al-Hayaly, C. Wagner, H. Schmidt, S. Timur, F.B. Barlas, E. Subasi, S. Ghosh, G. Hogarth, J. Inorg. Biochem. 141 (2014) 55.

[11] O. Grupče, M. Penavić, G. Jovanovski, J. Chem. Crystallogr. 24 (1994) 581.

[12] S. Stoyanov, T. Stoyanova, I. Antonov, P. Karagiannidis, P. Akrivos, Monatsch. Chem. 127 (1996) 495.

[13] S. Stoyanov, T. Stoyanova, P.D. Akrivos, Trends Appl. Spectrosc. 2 (1998) 89.

[14] M.M. Branda, N.J. Castellani, S.H. Tarulli, O.V. Quinzani, E.J. Baran, R.H. Contreras, Int. J. Quant. Chem. 89 (2002) 525.

[15] M. Vieites, D. Gambino, M. Gonz'alez, H. Cerecetto, S.H. Tarulli, O.V. Quinzani, E.J.

Baran, J. Coord. Chem. 59 (2006) 101.

[16] W.W. Porterfield, Inorganic Chemistry. A Unified Approach, second ed., Academic Press, San Diego, 1993.

[17] R.G. Pearson, Coord. Chem. Rev. 100 (1990) 403.

[18] S. Buck, G. Maas, J. Organomet. Chem. 691 (2006) 2774.

[19] S. Monira, S. Afrin, K.A. Azam, M.K. Hossain, D.A. Tocher, S. Ghosh, S. Rajbangshi, S.E.

Kabir, G. Hogarth, J. Organomet. Chem. 799-800 (2015) 281.

[20] M. Grohmann, G. Maas, Tetrahedron 63 (2007) 12172.

[21] M. Grohmann, S. Buck, L. Schäffler, G. Maas, Adv. Synth. Catal. 348 (2006) 2203.

[22] B.F.G. Johnson, J. Lewis, and D.A. Pippard, J. Chem. Soc., Dalton Trans. (1981) 407.

[23] CrysAlisPro; Oxford Diffraction: Yarnton, England, 2015.

[24] G.M. Sheldrick, Acta Crystallogr., Sect. A: Found. Crystallogr. 64 (2008) 112.

[25] (a) L. Palatinus, G. Chapuis, J. Appl. Cryst. 40 (2007) 786; (b) L. Palatinus, A. van der Lee, J. Appl. Cryst. 41 (2008) 975; (c) L. Palatinus, S.J. Prathapa, S. van Smaalen, J. Appl. Cryst. 45 (2012) 575 .

[26] G.M. Sheldrick, Acta Cryst. C71 (2015) 3.

[27] O.V. Dolomanov, L.J. Bourhis, R.J. Gildea, J.A.K. Howard, H. Puschmann, J. Appl. Crystallogr. 42 (2009) 339.

[28] M.J. Frisch et al., Gaussian 09, Revision E.01, Gaussian, Inc., Wallingford, CT, USA, 2009. [29] A.D. Becke, J. Chem. Phys. 98 (1993) 5648.

[30] C. Lee, W. Yang, R.G. Parr, Phys. Rev. B: Condens. Matter 37 (1988) 785. 
[31] (a) JIMP2, version 0.091, a free program for the visualization and manipulation of molecules: M.B. Hall, R.F. Fenske, Inorg. Chem. 11 (1972) 768; (b) J. Manson, C.E. Webster, M.B. Hall, Texas A\&M University, College Station, TX, 2006, http://www.chem. tamu.edu/jimp2/index.html.

[32] R.D. Adams, Z. Dawoodi, J. Am. Chem. Soc. 103, 1981, 6510.

[33] R.D. Adams, Z. Dawoodi, D.F. Foust, B.E. Segmüller, J. Am. Chem. Soc. 105, 1983, 831;

[34] R.D. Adams, Z. Dawoodi, D.F. Foust, B.E. Segmüller, Organometallics 2, 1983, 315.

[35] (a) M.R. Moni, M.J. Mia, S. Ghosh, D.A. Tocher, S.M. Mobin, T.A. Siddiquee, S.E. Kabir, Polyhedron 146, 2018, 154;

(b) T.S.M. Abedin, M.R. Moni, S. Ghosh, D.A. Tocher, G.M.G. Hossain, S.M. Mobin, S.E. Kabir, Polyhedron 152, 2018, 164;

(c) S. Ghosh, M.S.A. Mia, E. Begum, G.M.G. Hossain, S.E. Kabir, Inorg. Chim. Acta 384, 2012, 76 ;

(d) M.A. Khaleque, K.A. Azam, M.M. Karim, S. Ghosh, G. Hogarth, S.E. Kabir, Aust. J. Chem. 65, 2012, 773.

[36] (a) A.K. Raha, S. Ghosh, I. Hossain, S.E. Kabir, B.K. Nicholson, G. Hogarth, L. Salassa, J. Organomet. Chem. 696, 2011, 2153;

(b) S. Ghosh, K.N. Khanam, M.K. Hossain, G.M.G. Hossain, D.T. Haworth, S.V. Lindeman, G. Hogarth, S.E. Kabir, J. Organomet. Chem. 695, 2010, 1146;

(c) S. Ghosh, S.E. Kabir, S. Pervin, A.K. Raha, G.M.G. Hossain, D.T. Haworth, S.V. Lindeman, D.W. Bennett, T.A. Siddiquee, L. Salassa, H.W. Roesky, Dalton Trans. 2009, 3510;

(d) S.E. Kabir, J. Alam, S. Ghosh, K. Kundu, G. Hogarth, D.A. Tocher, G.M.G. Hossain, H.W. Roesky, Dalton Trans. 2009, 4458.

[37] (a) S. Ghosh, S.E. Kabir, S. Pervin, G.M.G. Hossain, D.T. Haworth, S.V. Lindeman, T.A. Siddiquee, D.W. Bennett, H.W. Roesky, Z. Anorg. Allg. Chem. 635, 2009, 76;

(b) S. Ghosh, S.E. Kabir, M. Khatun, D.T. Haworth, S.V. Lindeman, T.A. Siddiquee, D.W. Bennett, J Chem. Crystallogr. 39, 2009, 632;

(c) A.K. Raha, S. Ghosh, S.E. Kabir, B.K. Nicholson, D.A. Tocher, J. Organomet. Chem. 694, 2009, 752;

(d) S. Ghosh, F.K. Camellia, K. Fatema, M.I. Hossain, M.R. Al-Mamun, G.M.G. Hossain, G. Hogarth, S.E. Kabir, J. Organomet. Chem. 696, 2011, 2935. 
[38] S.A. Begum, M.A.H. Chowdhury, S. Ghosh, D.A. Tocher, M.G. Richmond, L. Yang, K.I. Hardcastle, E. Rosenberg, S.E. Kabir, RSC Adv. 8, 2018, 32672.

[39] (a) Here reactant A possesses 6 SEP with its arachno architecture traced to the corresponding five-vertex closo cluster. The increased electron count in product $\mathbf{B}$ (7 SEP) is responsible for the polyhedral expansion to the hypho cluster;

(b) D.M.P. Mingos, D.J. Wales, Introduction to Cluster Chemistry. Prentice-Hall, Englewood Cliffs, NJ, 1990.

[40] (a) M.J. Hossain, S. Rajbangshi, M.M.M. Khan, S. Ghosh, G. Hogarth, E Rosenberg, K.I. Hardcastle, M.G. Richmond, S.E. Kabir, J. Organomet. Chem. 767, 2014, 185;

(b) M.A.H. Chowdhury, M.R. Haque, S. Ghosh, S.M. Mobin, D.A. Tocher, G. Hogarth, M.G. Richmond, S.E. Kabir, H.W. Roesky, J. Organomet. Chem. 836-837, 2017, 68;

(c) M.M.M. Khan, M.M. Alam, S. Ghosh, A. Rahaman, D.A. Tocher, M.G. Richmond, S.E. Kabir, H.W. Roesky, J. Organomet. Chem. 843, 2017, 75.

[41] (a) M.R. Churchill, F.J. Hollander, R.A. Lashewycz, G.A. Pearson, J.R. Shapley, J. Am. Chem. Soc. 103, 1981, 2430;

(b) M.R. Churchill, F.J. Hollander, Inorg. Chem. 20, 1981, 4124. 
Table 1. Crystallographic and structural refinement data for 1-3.

\begin{tabular}{|c|c|c|c|}
\hline Compounds & 1 & 2 & 3 \\
\hline Empirical formula & $\mathrm{C}_{68} \mathrm{H}_{20} \mathrm{~N}_{4} \mathrm{O}_{48} \mathrm{Os}_{12} \mathrm{~S}_{8}$ & $\mathrm{C}_{34} \mathrm{H}_{8} \mathrm{~N}_{2} \mathrm{O}_{24} \mathrm{Os}_{6} \mathrm{~S}_{4}$ & $\mathrm{C}_{33} \mathrm{H}_{12} \mathrm{Cl}_{4} \mathrm{~N}_{2} \mathrm{O}_{21} \mathrm{Os}_{6} \mathrm{~S}_{4}$ \\
\hline Formula weight & 4199.76 & 2097.86 & 2183.69 \\
\hline Temperature $(\mathrm{K})$ & $150(1)$ & $150(1)$ & $150(1)$ \\
\hline Crystal system & monoclinic & monoclinic & Monoclinic \\
\hline Space group & $P c$ & $P 2_{1}$ & $P 2{ }_{1} / c$ \\
\hline$a(\AA)$ & $15.1150(3)$ & $7.80893(11)$ & $16.5084(4)$ \\
\hline$b(\AA)$ & $12.9090(3)$ & $15.2764(2)$ & $12.7404(3)$ \\
\hline c $(\AA)$ & $12.2226(3)$ & $18.6629(2)$ & $23.5289(4)$ \\
\hline$\beta\left(^{\circ}\right)$ & $102.505(2)$ & $91.1816(12)$ & $101.599(2)$ \\
\hline Volume $\left(\AA^{3}\right)$ & $2328.29(9)$ & $2225.86(5)$ & $4847.65(17)$ \\
\hline $\mathrm{Z}$ & 1 & 2 & 4 \\
\hline Density (calculated) $\left(\mathrm{g} / \mathrm{cm}^{3}\right)$ & 2.995 & 3.13 & 2.992 \\
\hline Absorption coefficient $\left(\mathrm{mm}^{-1}\right)$ & 16.574 & 17.336 & 16.136 \\
\hline$F(000)$ & 1880 & 1876 & 3920 \\
\hline Crystal size $\left(\mathrm{mm}^{3}\right)$ & $0.14 \times 0.12 \times 0.06$ & $0.16 \times 0.14 \times 0.02$ & $0.20 \times 0.16 \times 0.06$ \\
\hline $2 \theta$ range data collection $\left(^{\circ}\right)$ & 6.36 to 51.994 & 5.764 to 57.016 & 6.27 to 54 \\
\hline Reflections collected & 35786 & 35243 & 81593 \\
\hline Independent reflections $\left[R_{\text {int }}\right]$ & $9128\left[R_{\text {int }}=0.0477\right]$ & $9916\left[R_{\mathrm{int}}=0.0421\right]$ & $10545\left[R_{\mathrm{int}}=0.0540\right]$ \\
\hline Data/restraints/parameters & $9128 / 2 / 626$ & $9916 / 1 / 621$ & $10545 / 0 / 631$ \\
\hline Goodness-of-fit on $F^{2}$ & 0.994 & 1.063 & 1.059 \\
\hline Final $R$ indexes $[I>=2 \sigma(I)]$ & $R_{1}=0.0208, w R_{2}=0.0397$ & $R_{1}=0.0283, w R_{2}=0.0590$ & $R_{1}=0.0271, w R_{2}=0.0568$ \\
\hline Final $R$ indexes [all data] & $R_{1}=0.0218, w R_{2}=0.0401$ & $R_{1}=0.0298, w R_{2}=0.0598$ & $R_{1}=0.0338, w R_{2}=0.0603$ \\
\hline Largest diff. peak/hole $\left(\mathrm{e}^{-3}\right)$ & 1.15 and -0.91 & 1.74 and -1.52 & 2.01 and -1.61 \\
\hline
\end{tabular}



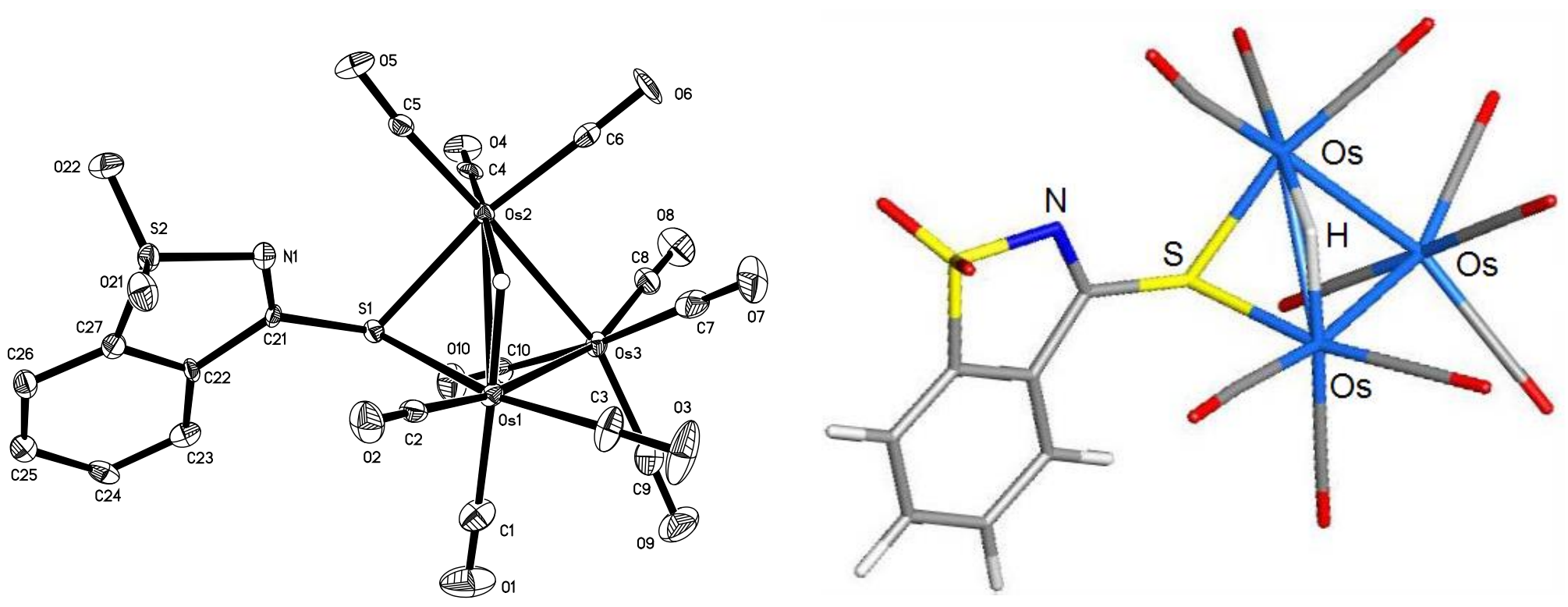

Fig. 1. ORTEP drawing of the molecular structure of $\left[\mathrm{HOs}_{3}(\mathrm{CO})_{10}(\mu-\mathrm{S}\right.$-tsac) $)(\mathbf{1}$, left) showing $50 \%$ probability thermal ellipsoids and the DFT-optimized structure of A (right). Ring hydrogens in the solid-state structure are omitted for clarity. Selected crystallographic bond lengths $(\AA)$ and angles $\left({ }^{\circ}\right)$ for 1: Os(1)-Os(2) 2.8451(5), Os(1)-Os(3) 2.8460(6), Os(2)-Os(3) 2.8524(5), Os(1)-S(1) 2.425(2), Os(2)-S(1) 2.421(2), S(1)-C(21) 1.781(9), N(1)-C(21) 1.261(11), Os(2)-Os(1)-Os(3) 60.159(13), Os(1)-Os(2)-Os(3) 59.937(13), Os(1)-Os(3)-Os(2) 59.905(13), Os(2)-S(1)-Os(1) 71.89(7), C(21)-S(1)-Os(1) 105.4(3), C(21)-S(1)-Os(2) 111.1(3). 

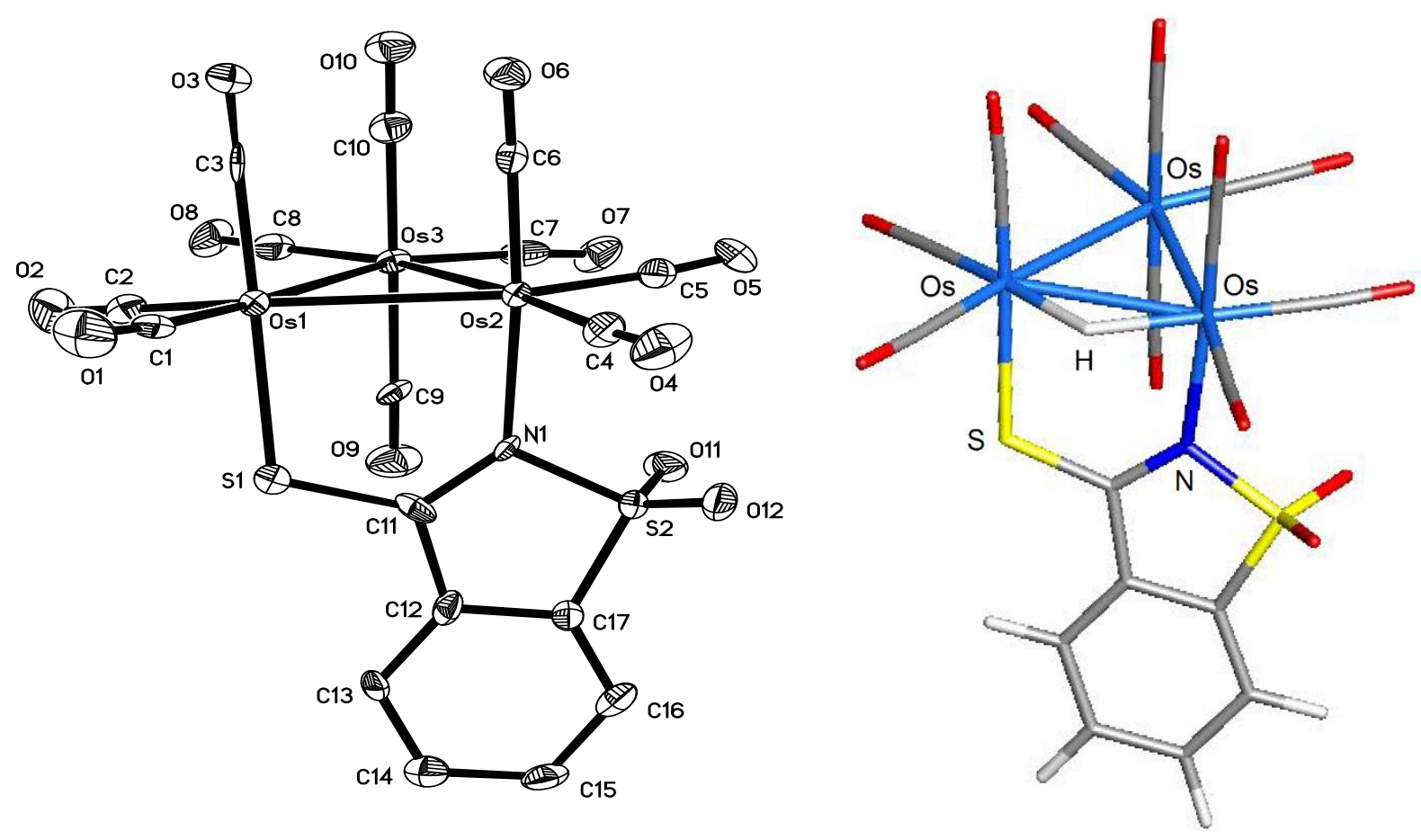

Fig. 2. ORTEP drawing of the molecular structure of $\left[\mathrm{HOs}_{3}(\mathrm{CO})_{10}(\mu-\mathrm{N}, \mathrm{S}-1,3-\mathrm{tsac})\right](2$, left $)$ showing $50 \%$ probability thermal ellipsoids and the DFT-optimized structure of $\mathbf{E}$ (right). Ring hydrogens on the heterocyclic ligand in the solid-state structure are omitted for clarity. Selected crystallographic bond lengths (Å) and angles $\left(^{\circ}\right)$ : Os(1)-Os(2) 2.9301(6), Os(1)-Os(3) 2.9052(7), Os(2)-Os(3) 2.8776(6), Os(1)$\mathrm{S}(1)$ 2.434(3), Os(2)-N(1) 2.160(10), C(11)-S(1) 1.672(13), C(11)-N(1) 1.321(17), Os(3)-Os(1)-Os(2) 59.093(16), Os(3)-Os(2)-Os(1) 60.023(16), Os(2)-Os(3)-Os(1) 60.884(15), C(11)-S(1)-Os(1) 109.1(5), C(11)-N(1)-Os(2) 130.5 (8), Os(2)-Os(1)-S(1) 87.91 (8), S(1)$\mathrm{C}(11)-\mathrm{N}(1) 126.6(10), \mathrm{C}(1)-\mathrm{Os}(1)-\mathrm{Os}(2) 119.6(4), \mathrm{C}(4)-\mathrm{Os}(2)-\mathrm{Os}(1) 117.7$ (4). 


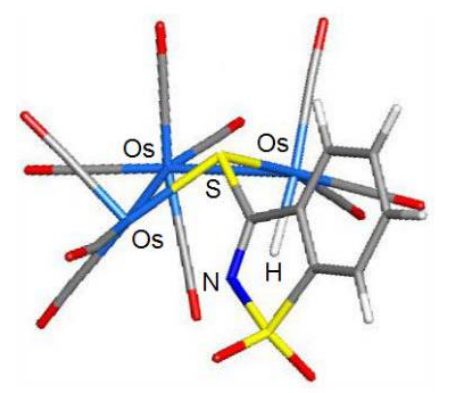

TSAB

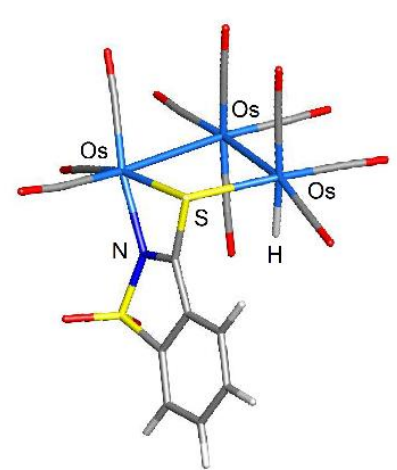

B

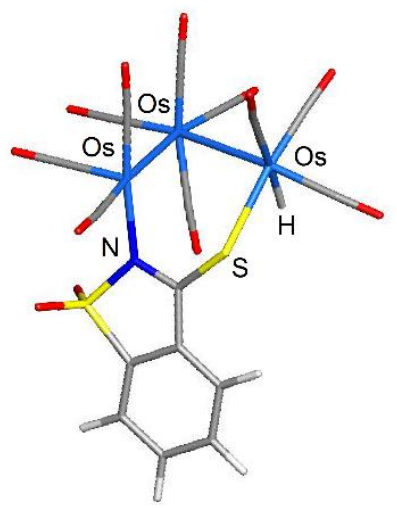

TSBC

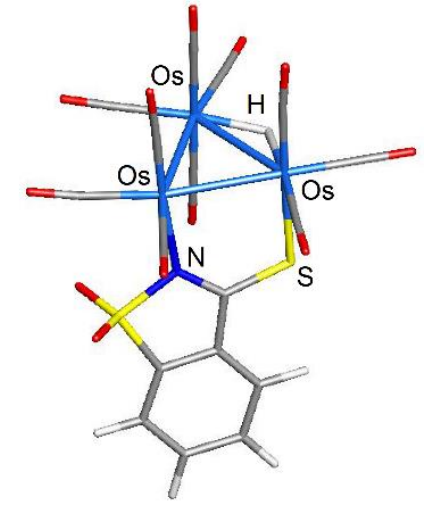

C

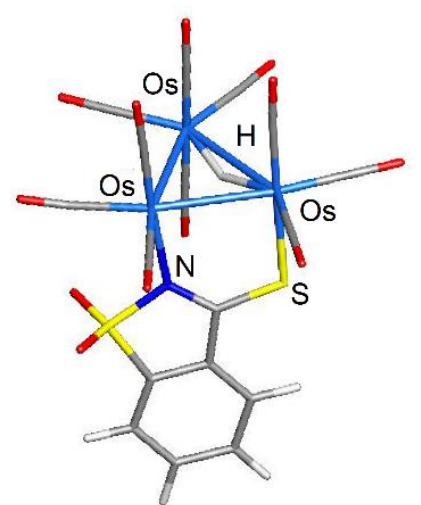

TSCD

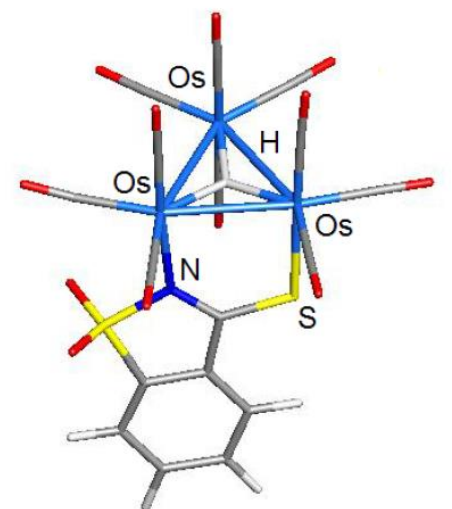

D

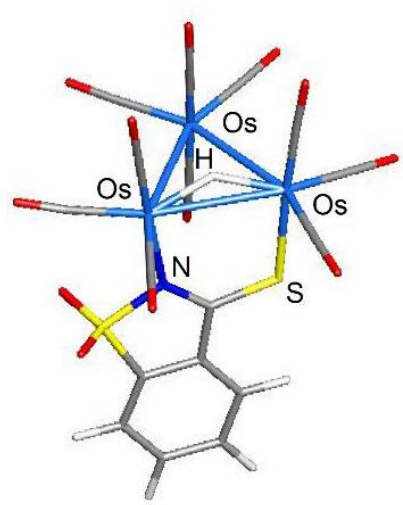

TSDE

Fig. 3. DFT-optimized structures for the isomerization reaction of $\left[\mathrm{HOs}_{3}(\mathrm{CO})_{10}(\mu-\mathrm{S}\right.$-tsac) $](\mathbf{A})$ to give $\left[\mathrm{HOs}_{3}(\mathrm{CO})_{10}(\mu-\mathrm{N}, \mathrm{S}-1,3\right.$-tsac $\left.)\right](\mathbf{E})$. The optimized structures of $\mathbf{A}$ and $\mathbf{E}$ are depicted in Figs. 1 and 2, respectively. 


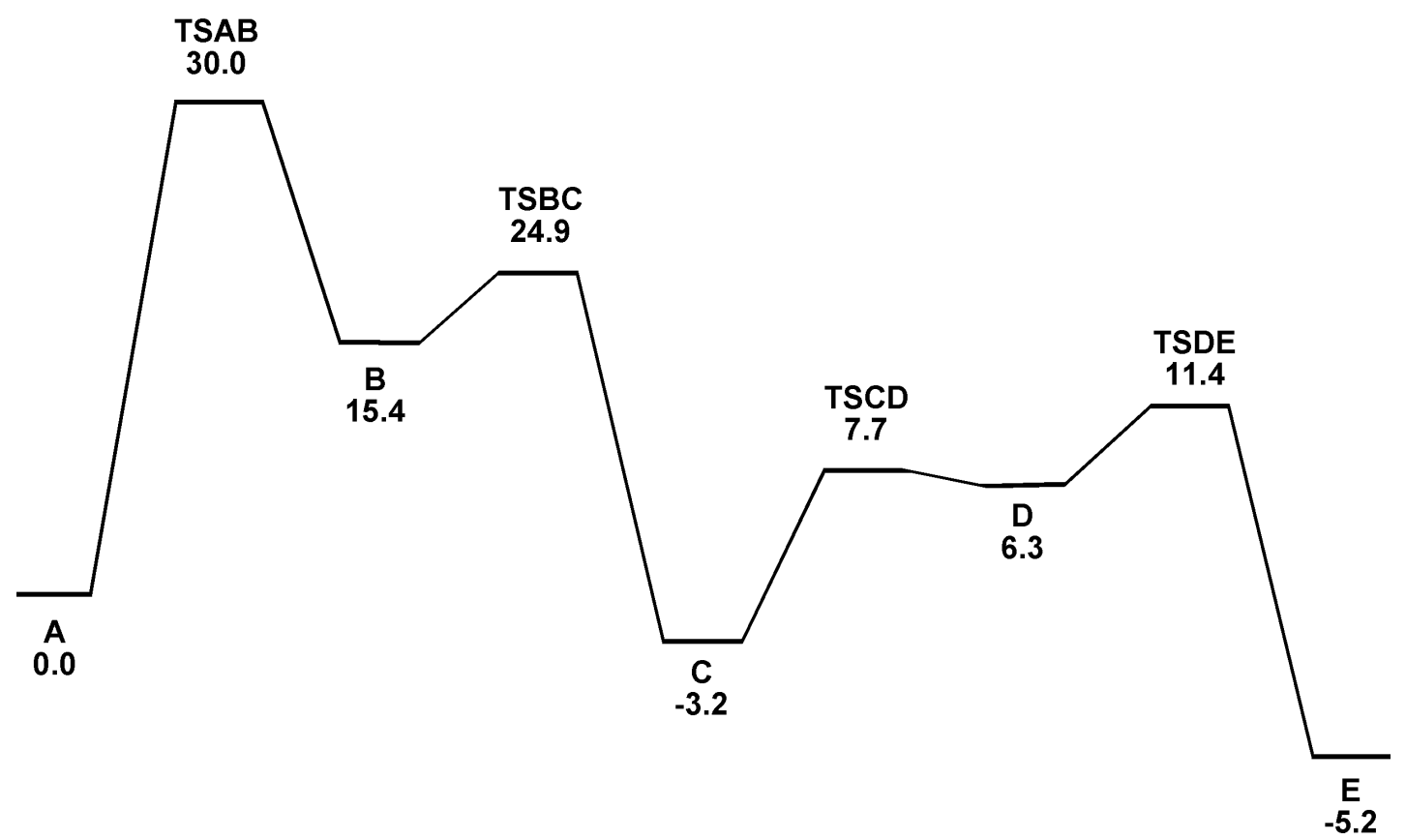

Fig. 4. Energy profile for the isomerization reaction of $\left[\mathrm{HOs}_{3}(\mathrm{CO})_{10}(\mu-\mathrm{S}\right.$-tsac)] (A) to give $\left[\mathrm{HOs}_{3}(\mathrm{CO})_{10}(\mu-\mathrm{N}, \mathrm{S}-1,3\right.$-tsac) $](\mathbf{E})$. Energy values $(\Delta \mathrm{G})$ are in $\mathrm{kcal} / \mathrm{mol}$ relative to $\mathbf{A}$. 

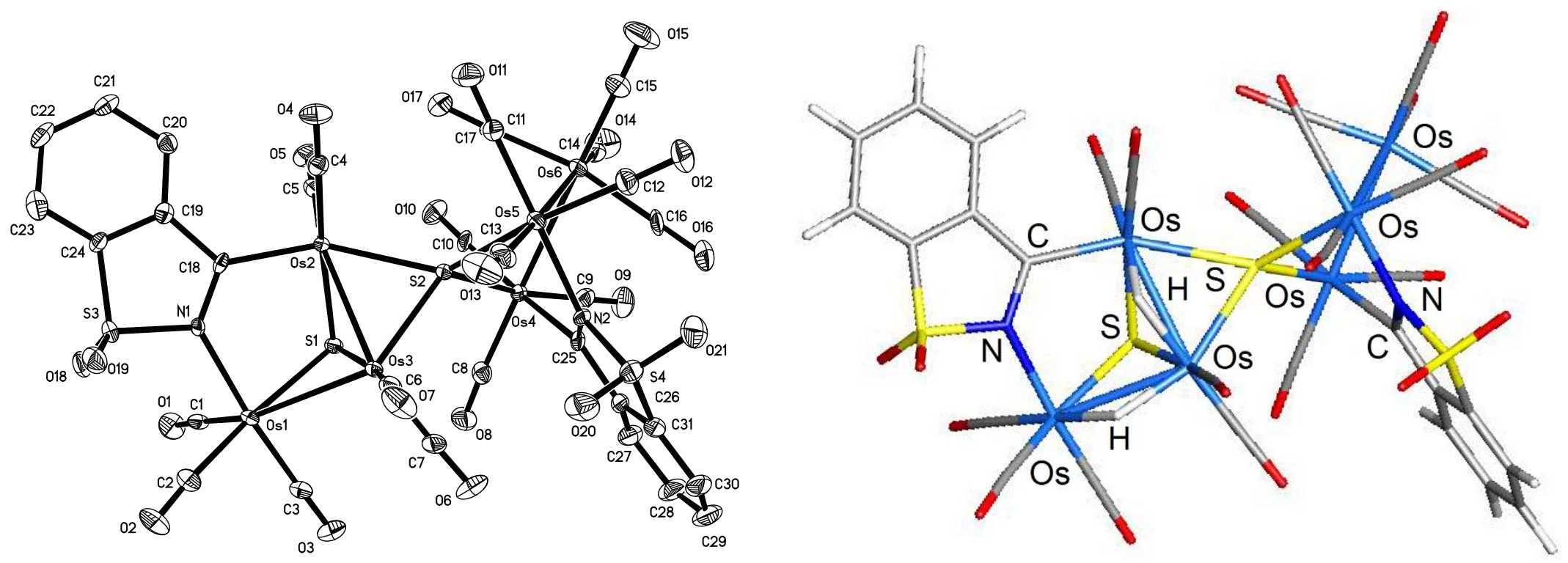

Fig. 5. ORTEP drawing of the molecular structure of $\left[\mathrm{H}_{2} \mathrm{Os}_{6}(\mathrm{CO})_{17}\left(\mu-\mathrm{C}, \mathrm{N}-1,2-\mathrm{C}_{6} \mathrm{H}_{4} \mathrm{CNSO}_{2}\right)_{2}\left(\mu_{3}-\mathrm{S}\right)\left(\mu_{4}-\mathrm{S}\right)\right]$ (3, left) showing $50 \%$ probability thermal ellipsoids and the DFT-optimized structure of F1 (right). The ring hydrogens on the heterocyclic ligand in the solidstate structure are omitted for clarity. Selected crystallographic bond lengths $(\AA)$ and angles $\left({ }^{\circ}\right)$ : Os(1)-Os(3) 2.9184(3), Os(2)-Os(3) 2.8031(3), Os(1)-S(1) 2.4040(14), Os(2)-S(1) 2.4190(15), Os(3)-S(1) 2.4028(15), Os(1)-N(1) 2.135(5), Os(2)-C(18) 2.017(6), N(1)C(18) 1.334(7), Os(2)-S(2) 2.4862(15), Os(3)-S(2) 2.4183(14), Os(4)-S(2) 2.4577(15), Os(5)-S(2) 2.4448(14), Os(5)-Os(6) 2.8933(3), Os(4)-Os(6) 2.8962(3), Os(4)-C(25) 2.079(6), Os(5)-N(2) 2.119(5), N(2)-C(25) 1.319(8), Os(2)-Os(3)-Os(1) 81.649(9), Os(4)-Os(6)Os(5) 76.466(9), Os(1)-S(1)-Os(2) 101.74(5), Os(2)-S(1)-Os(3) 71.09(4), Os(1)-S(1)-Os(3) 74.77(4), Os(1)-N(1)-C(18) 128.8(4), Os(2)-C(18)-N(1) 120.7(4), Os(2)-S(2)-Os(3) 69.70(4), Os(4)-S(2)-Os(5) 93.91(5), S(2)-Os(5)-Os(6) 83.57(3), S(2)-Os(4)-Os(6) 83.29(3), Os(2)-C(18)-N(1) 120.7(4), N(1)-Os(1)-S(1) 85.68(11), Os(5)-N(2)-C(25) 125.2(4), C(2)-Os(1)-Os(3) 116.0(2), C(6)-Os(3)Os(1) 119.12(18), C(6)-Os(3)-Os(2) 119.61(19), C(4)-Os(2)-Os(3) 118.61(19). 


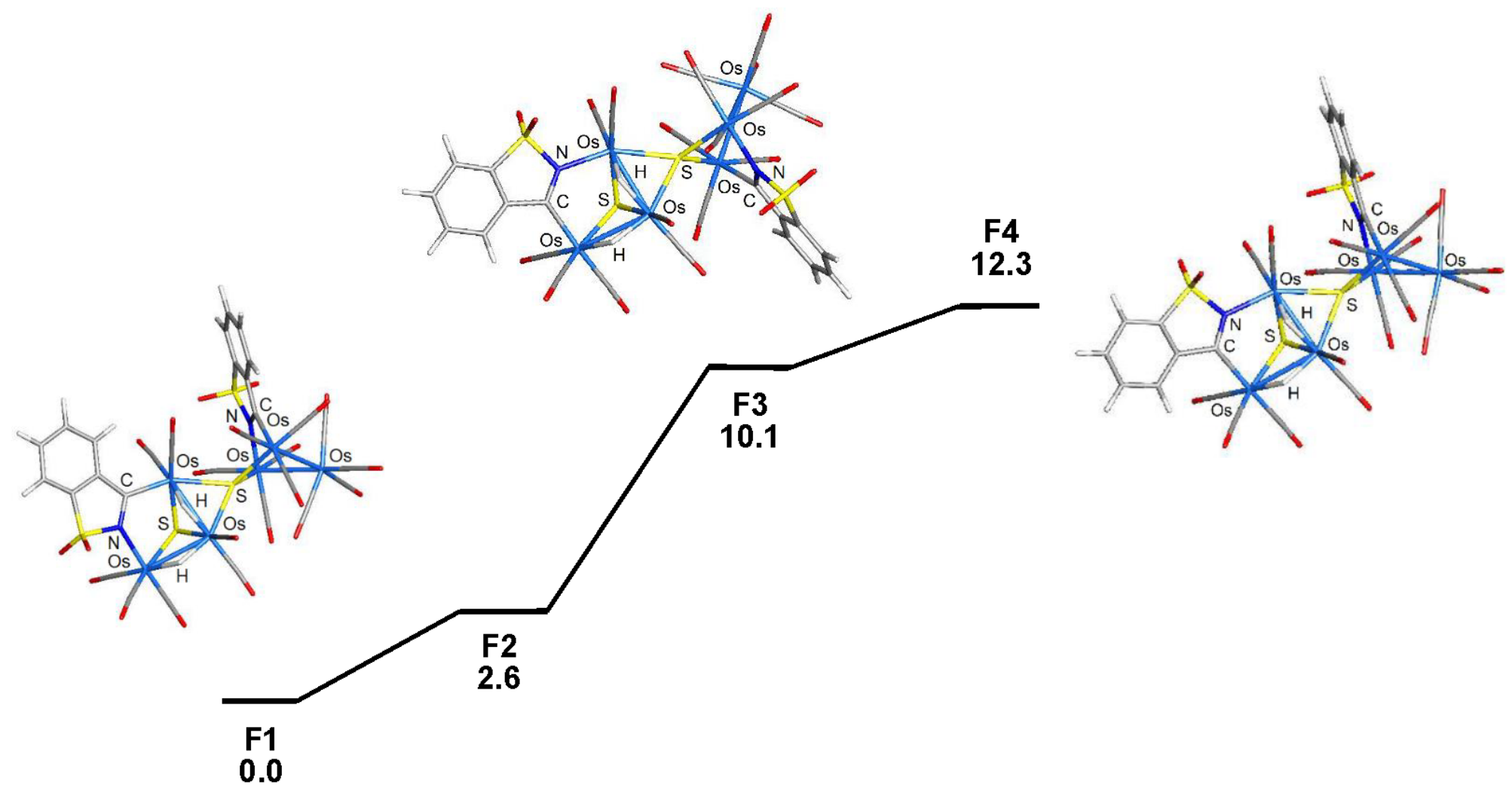

Fig. 6. Energy ordering for the different structures based on $\left[\mathrm{Os}_{6}(\mathrm{CO})_{17}\left\{\mu-\kappa^{1}(\mathrm{~N}), \eta^{1}(\mathrm{C})-\mathrm{C}_{6} \mathrm{H}_{4} \mathrm{CNSO}_{2}\right\}_{2}(\mu-\mathrm{H})_{2}\left(\mu_{3}-\mathrm{S}\right)\left(\mu \mu_{4}-\mathrm{S}\right)\right]$ and the DFToptimized structures of F2-F4 (see Fig. 5 for the optimized structure of F1). The quoted energy values $(\Delta \mathrm{G})$ are in kcal/mol relative to F1. 


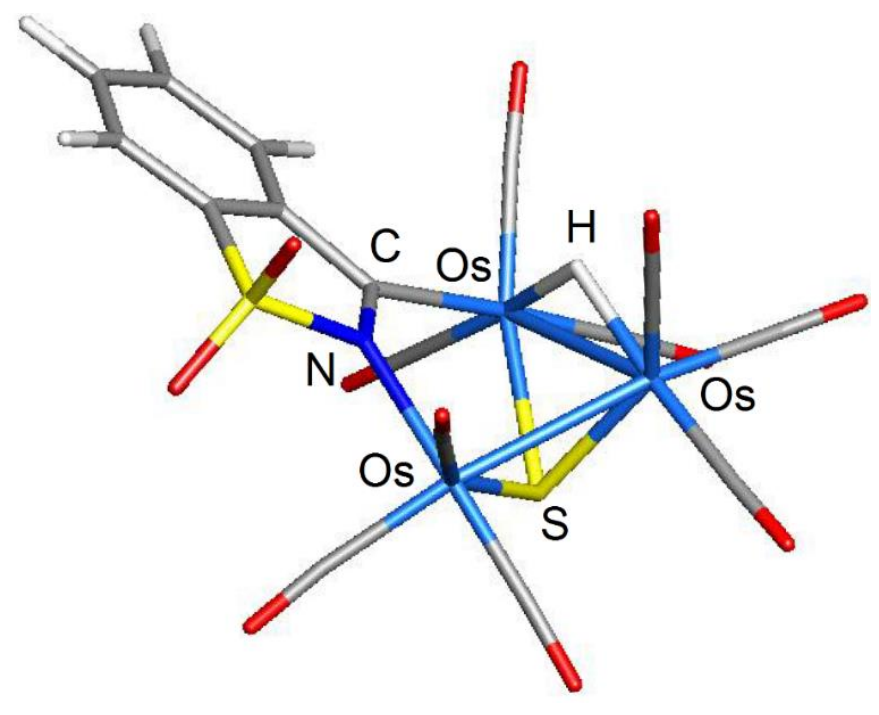

Fig. 7. DFT-optimized structure of the intermediate cluster $\left[\mathrm{HOs}_{3}(\mathrm{CO})_{9}(\mu-\mathrm{N}, \mathrm{C}-1,2-\right.$ $\left.\left.\mathrm{C}_{6} \mathrm{H}_{4} \mathrm{CNSO}_{2}\right)_{2}\left(\mu_{3}-\mathrm{S}\right)\right]$ produced from $\left[\mathrm{HOs}_{3}(\mathrm{CO})_{10}(\mu-\mathrm{N}, \mathrm{S}-1,3-\right.$ tsac $\left.)\right](2)$ upon thermolysis. 


\section{Graphical Abstract}

\section{Activation of thiosaccharin at a polynuclear osmium cluster}

Tamanna Pinky, Md. Matiar Rahman, Shishir Ghosh *, Kazi A. Azam, Md. Jadu Mia, Md. Mahbub Alam, Derek A. Tocher, Michael G. Richmond, Shariff E. Kabir *

The reactivity of thiosaccharin at the labile triosmium cluster $\left[\mathrm{Os}_{3}(\mathrm{CO})_{10}(\mathrm{NCMe})_{2}\right]$ has been investigated.
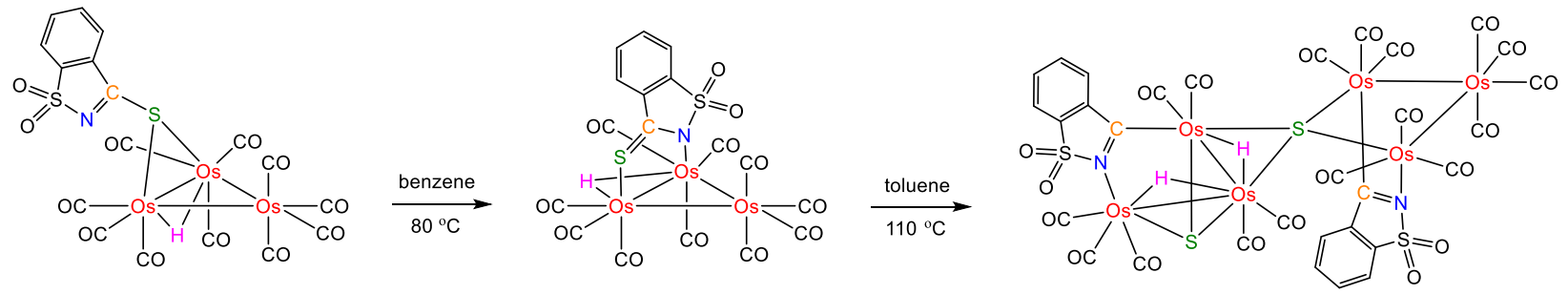